\title{
Effect of some gastrointestinal hormones on motor and electrical activity of the digestive tract in the conscious cat
}

\author{
BY MAURICE ROCHE', MONIQUE DESCROIX-VAGNE', SONIA BENOUALI ${ }^{1}$ \\ AND JEAN-ALAIN CHAYVIALLE' \\ ${ }^{1}$ Laboratoire de Physiologie Appliquée et Pharmacologie, Université de Savoie, BP 1104. \\ 73011 Chambéry, France \\ ${ }^{2}$ INSERM, Unité 45, Hôpital E. Herriot, Lyon, France
}

(Received 21 February 1991-Accepted 25 March 1992)

\begin{abstract}
Three peptides structurally related to gastrin and known to be full agonists of antral motility in the conscious cat, pentagastrin (PG), cholecystokinin (CCK) and synthetic octapeptide of cholecystokinin (OP-CCK), were compared in relation to antral and duodenal electrical activity. They induced the same antral effect in eliciting an increase in the basal electrical rhythm (BER) and a short-lasting decrease in the frequency of the bursts of spikes. The electrical changes were correlated with lumen pressure changes measured in parallel, consisting of a decrease in the frequency of high-amplitude peaks and an increase in low-amplitude peaks. The additive effect of $P G$ and $C C K$ shows that the peptides are full agonists for antral electrical activity, as they are for antral motility and acid secretion. In contrast to the antrum, the three peptides increased the frequency of the duodenal spike bursts, CCK and OP-CCK decreased the BER frequency, while PG increased BER slightly. The increase in antral and duodenal BER obtained after a beef-liver meal, which produced a large endogenous gastrin release, suggests a major role for gastrin in antral motility induced by feeding, at least in the cat.
\end{abstract}

Gastrointestinal hormones: Motor and electrical activity

Although gastrointestinal motility of the cat shows some unusual features, in common with other species, different regions of the gastrointestinal tract show a characteristic basal electrical rhythm (BER) on which spike activity and, hence, contractions are superimposed (Roche et al. 1982). It has been shown that pentagastrin (PG), cholecystokinin (CCK) and the synthetic octapeptide of CCK (OP-CCK) are full agonists for the stimulation of antral motility (Desvigne et al. 1980) and also for acid secretion (Way, 1971), but not for pepsin secretion (Desvigne et al. 1980). The main purpose in the present study was to compare the effect of these three peptides on antral and duodenal electrical activity and to correlate the antral electromyographic activity response to their effect on antral intralumen pressure. Further, we investigated whether or not the gastrin-related peptides could be responsible for the different postprandial patterns of the gastric BER that we reported previously, in relation to the nature of the meal (increase of antral BER after beef-liver meal, no change after canned food (Roche et al. 1982)).

\section{METHODS}

In three cats (one female and two males), weighing $3-4.5 \mathrm{~kg}$, a modified Thomas cannula (Thomas, 1941) was surgically implanted under pentobarbital anaesthesia, in the fundic part of the stomach. A duodenal cannula was also inserted (Vagne et al. 1982) and was kept open during the experiments to prevent any biliary reflux. Moreover, the animals were equipped with electrodes made of insulated nichrome wire $(0.1 \mathrm{~mm}$ diameter, $700 \mathrm{~mm}$ length), which were inserted in pairs, $2 \mathrm{~mm}$ apart, through the serosa and muscular layers 
using a needle as a trocar. A total of four pairs of electrodes were implanted on the antrum at $30,20,10$ and $5 \mathrm{~mm}$ from the pylorus. Two other pairs were fixed on the duodenum at 10 and $20 \mathrm{~mm}$ from the pylorus. The free ends of all electrodes were passed subcutaneously from the abdomen to the dorso-scapular region, fixed to the skin and placed in a leather bag secured by a thoracic harness. The exact positions of the electrodes were determined post mortem.

Experiments were started 1 week after the electrode implantation. The animals had completely recovered after $2 \mathrm{~d}$. The frequency of the tests was not more than twice weekly. The animals were fasted for about $18 \mathrm{~h}$ before each test. They were maintained in a harness. A continuous intravenous infusion of saline $(9 \mathrm{~g} \mathrm{NaCl} / \mathrm{l})$ was given at a rate of $13 \mathrm{ml} / \mathrm{h}$ by means of a catheter placed in the front leg vein and connected to a pump (Harvard Apparatus, USA). The gastric and duodenal cannulas were opened and the stomach was washed with water.

Recording of electrical activity

The electrodes were connected to an electroencephalograph apparatus (REEGA VIII; AVAR, Paris, France), using a rotating multichannel connector. The time constant was $0.1 \mathrm{~s}$. Frequency of BER and number of spike bursts were determined at $10 \mathrm{~min}$ intervals by direct calculation of the electromyographic (EMG) recordings. Each animal was its own control and the statistical analysis compared the variations between basal and stimulated patterns by both the $t$ test for paired values and the Mann-Whitney $\mathrm{U}$ test.

\section{Recording of antral intralumen pressure}

An open-tip polyethylene tube ( $1 \mathrm{~mm}$ i.d.), cut obliquely with a hole opposite the bisection, was introduced through the gastric cannula and attached to it when placed $10 \mathrm{~mm}$ from the pylorus. The catheter was perfused with water at a rate of $6 \mathrm{ml} / \mathrm{h}$ (Technicon pump; Domont, France). It was connected via a pressure transducer (Statham P 23 BB; GodartStatham, Bilthoven, The Netherlands) to an amplifier (Statham SC 1000) and to a potentiometric recorder (Servotrace; Sefram, Paris, France).

\section{Collection of gastric juice}

A device was attached to the gastric cannula to collect gastric juice in graduated tubes every $15 \mathrm{~min}$. Volume and acid concentrations were determined in order to verify that the infusion of the test substances was correct. As these findings simply confirmed previous results (Desvigne et al. 1980; Vagne et al. 1982) they are not presented.

\section{Test substances}

PG (Peptavlon; ICI Limited, Macclesfield, Cheshire) was given at doses of 0-5, 4, 8 and $32 \mu \mathrm{g} / \mathrm{kg}$ per $\mathrm{h}$. PG at 0.5 and $8 \mu \mathrm{g} / \mathrm{kg}$ per $\mathrm{h}$ was also given during a continuous infusion of 4 Ivy Dog Units (IDU) CCK $/ \mathrm{kg}$ per h. CCK (GIH Research Laboratories, Stockholm, Sweden) was given at doses of 1, 4 and 16 IDU/kg per h. OP-CCK (Sq 19844; Squibb, New Brunswick, NJ, USA) was given at doses of $0 \cdot 25,1,2$ and $4 \mu \mathrm{g} / \mathrm{kg}$ per h. Only one dose was infused daily. For each dose, three experiments were repeated in each cat, not more than three times weekly, in a randomized order.

\section{Blood determination}

Gastrin was measured in serum samples collected during the basal period, twice at 15 min intervals and 30,60 and $90 \mathrm{~min}$ after the meal which was either $60 \mathrm{~g}$ chopped fresh liver or canned food (Fido; Quaker-France, Marseilles, France). The determination was made for four cats once weekly using about $2 \mathrm{ml}$ blood.

Gastrin was determined by the technique previously described and validated (Vagne et 
al. 1987), using rabbit anti-gastrin serum obtained after immunization against synthetic human gastrin I 2-17 (ICI Ltd) conjugated to bovine albumin through carbodiimide condensation. Synthetic human gastrin I 1-17 was used as standard and for iodination with ${ }^{125} \mathrm{I}$ by the chloramine T method (Hunter \& Greenwood, 1962).

\section{RESULTS}

\section{Fasted patterns}

Basal period. After an $18 \mathrm{~h}$ fast, the mean frequency of BER in the antrum was 4.7 (SEM $0.02 ; n 312$ ) cycles per min. For each cat, the mean was respectively 4.51 (SEM $0.02 ; n$ 104), 4.79 (SEM $0.02 ; n$ 104), 4.94 (SEM $0.02 ; n$ 104). The BER basal frequencies differed statistically between cats ( $F$-test, $P<0.01$ ). However, this variation was very small, equal to $9 \%$ of the mean obtained with all the cats. In the duodenum the mean frequency was $19 \cdot 2$ (SEM 0.04 ; $n$ 282). The mean for each cat was $19 \cdot 3$ (SEM 0.04; $n$ 94), $19 \cdot 18$ (SEM 0.04; $n$ 94), $19 \cdot 16$ (SEM $0 \cdot 09 ; n$ 94). The individual means did not differ.

The bursts of spike potentials appeared superimposed cyclically on one to two consecutive antral slow waves, occupying approximately $30 \%$ of the recording time. In the duodenum, spike potentials occurred as series of bursts at a mean frequency (per $10 \mathrm{~min}$ ) of $5 \cdot 8$ (SEM $0 \cdot 2 ; n 112, n$ being 38,37 and 37 respectively for each cat).

The parallel recording of antral contractions and EMG activity is shown in Fig. 1. Spiking activity was related to intralumen pressure changes recorded as single peaks of high amplitude, usually higher than $200 \mathrm{~mm}$ of water pressure, whereas BER was in complete correlation with low-amplitude peaks ranging from 30 to $200 \mathrm{~mm}$ of water pressure.

\section{Effect of gastrointestinal hormones}

$B E R$ on the antrum. The three peptides induced an increase in the BER as shown in Fig. 2. PG induced the strongest increase, about $40 \%$, with a dose of $8 \mu \mathrm{g}$. The increase was

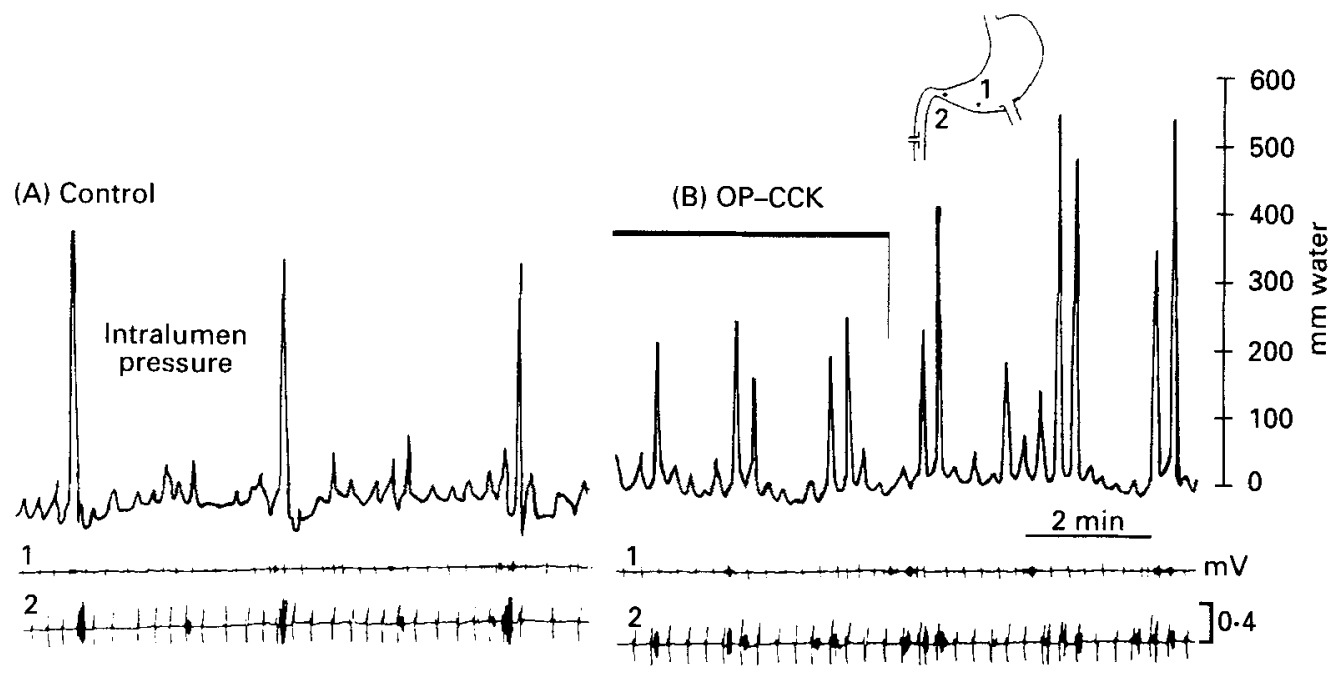

Fig. 1. Simultaneous recording of antral intralumen pressure and electrical activity in the conscious cat, during control and a synthetic octapeptide of cholecystokinin (OP-CCK) intravenous infusion ( $2 \mu \mathrm{g} / \mathrm{kg}$ per h). During control infusion, spiking activity was associated with high-amplitude peaks, while during OP-CCK stimulation the spike bursts were more frequent and associated with lower-amplitude peaks than during the control periods. For details of animals and procedures, see pp. 371-372. 


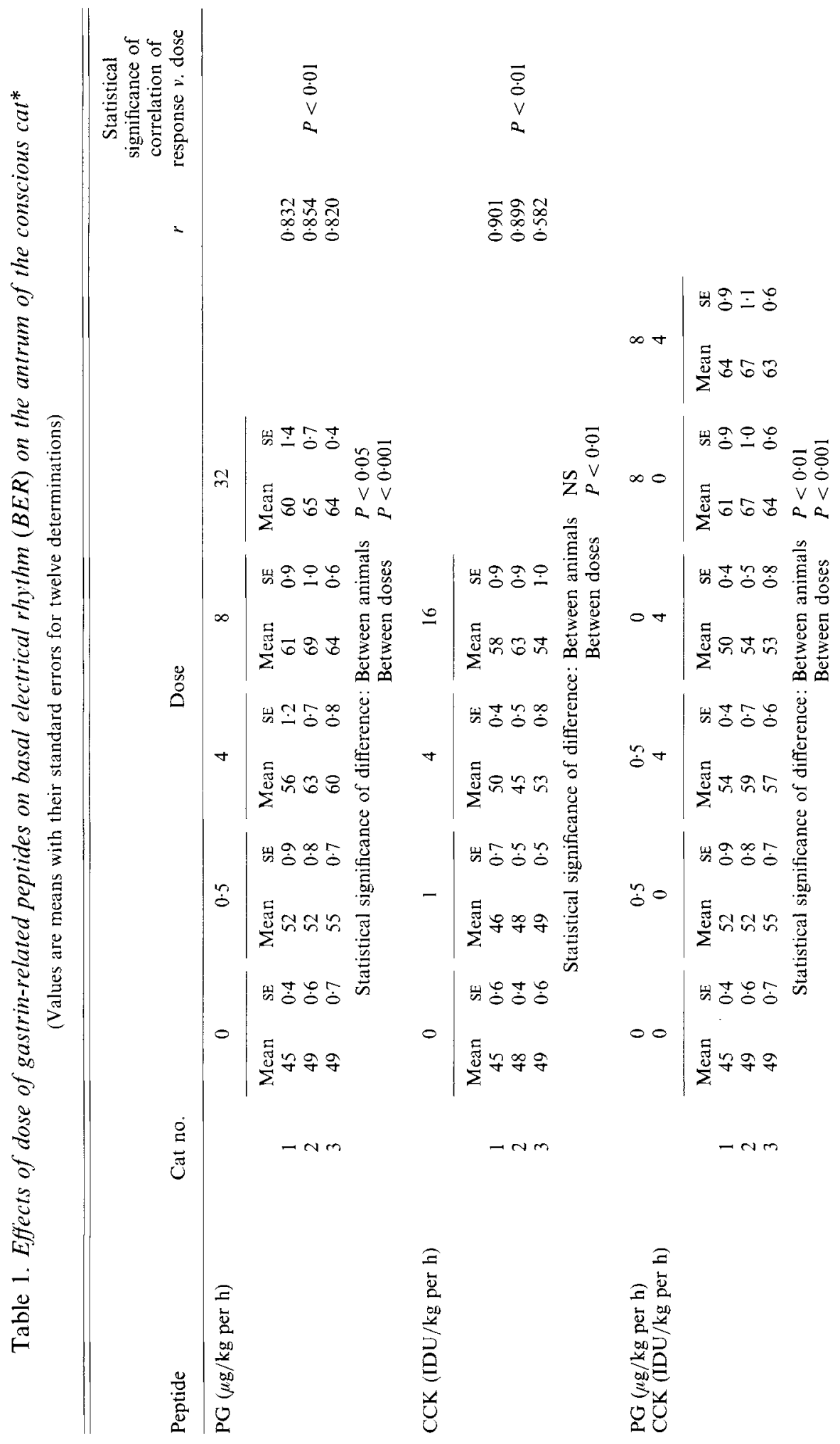




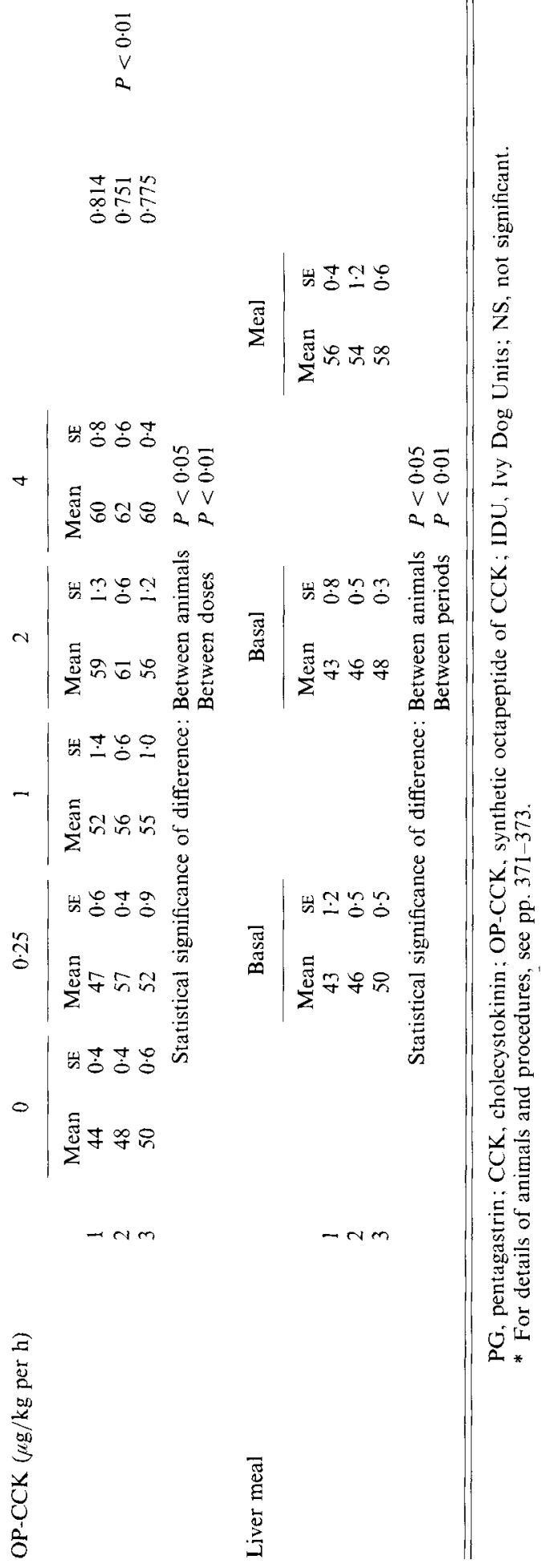




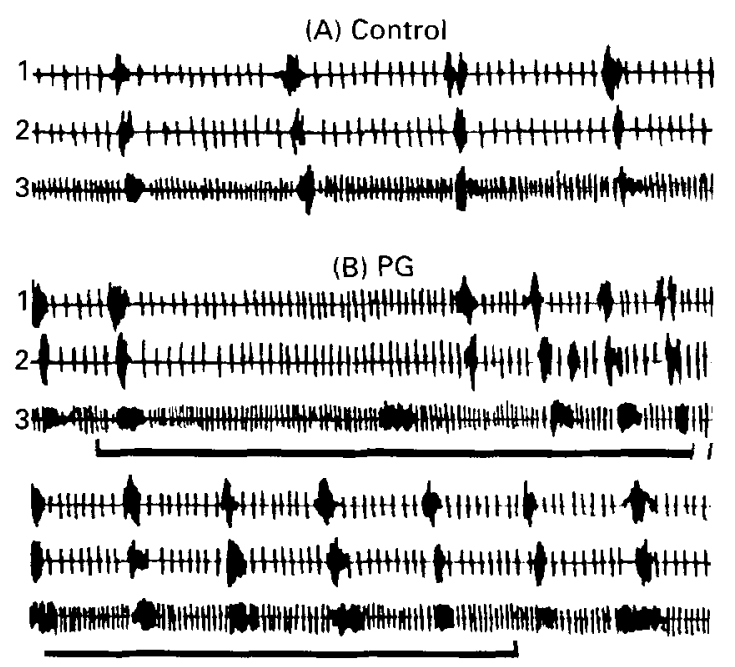

(C) $\mathrm{CCK}$

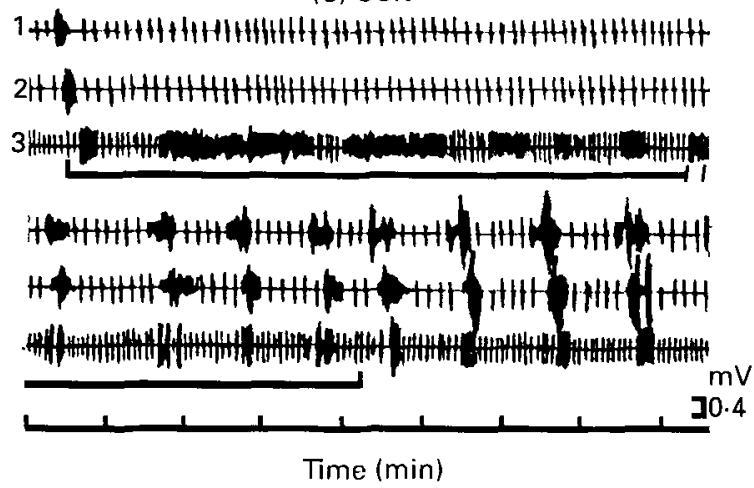

Fig. 2. Typical recording of electrical activity of antrum (1 and 2) and duodenum (3) in one cat. (A) Electrical activity before infusion, (B) electrical activity during the beginning (set 1) and during the end (set 2) of administration for $2 \mathrm{~h}$ of pentagastrin ( $\mathrm{PG} ; 32 \mu \mathrm{g} / \mathrm{kg}$ per h), (C) electrical activity during the beginning (part 1) and during the end (part 2) of administration of cholecystokinin (CCK; 4 Ivy Dog Units/kg per h). (-), Intravenous infusion. The increase in the basal electrical rhythm induced in the antrum by both peptides, the short-lasting decrease in spike activity in the antrum and its increase in the duodenum can be seen. For details of animals and procedures, see pp. 371-372.

linearly related to the doses of peptide over $0-8 \mu \mathrm{g}$. There was no increase between 8 and $32 \mu \mathrm{g}$ (Table 1). CCK added to PG induced an additive effect at the low dose of PG (Fig. $3)$; the response was higher than that to each stimulant alone $(P<0.05$ in each case). No potentiation was observed at the maximal dose of $\mathrm{PG}(P>0 \cdot 1)$.

$B E R$ on the duodenum. CCK and OP-CCK induced a statistically significant decrease in the BER (Table 2), while PG produced a slight but significant increase in two of three cats (Fig. 4 and Table 2). In the duodenum PG activity was different from that for the intestinal hormones.

Spiking activity on the antrum. The three peptides induced a similar effect on the spike activity. The frequency of spike bursts decreased temporarily (range 6-16 min) and then increased to values at least equal to basal values and sometimes higher (Fig. 2). The spike 

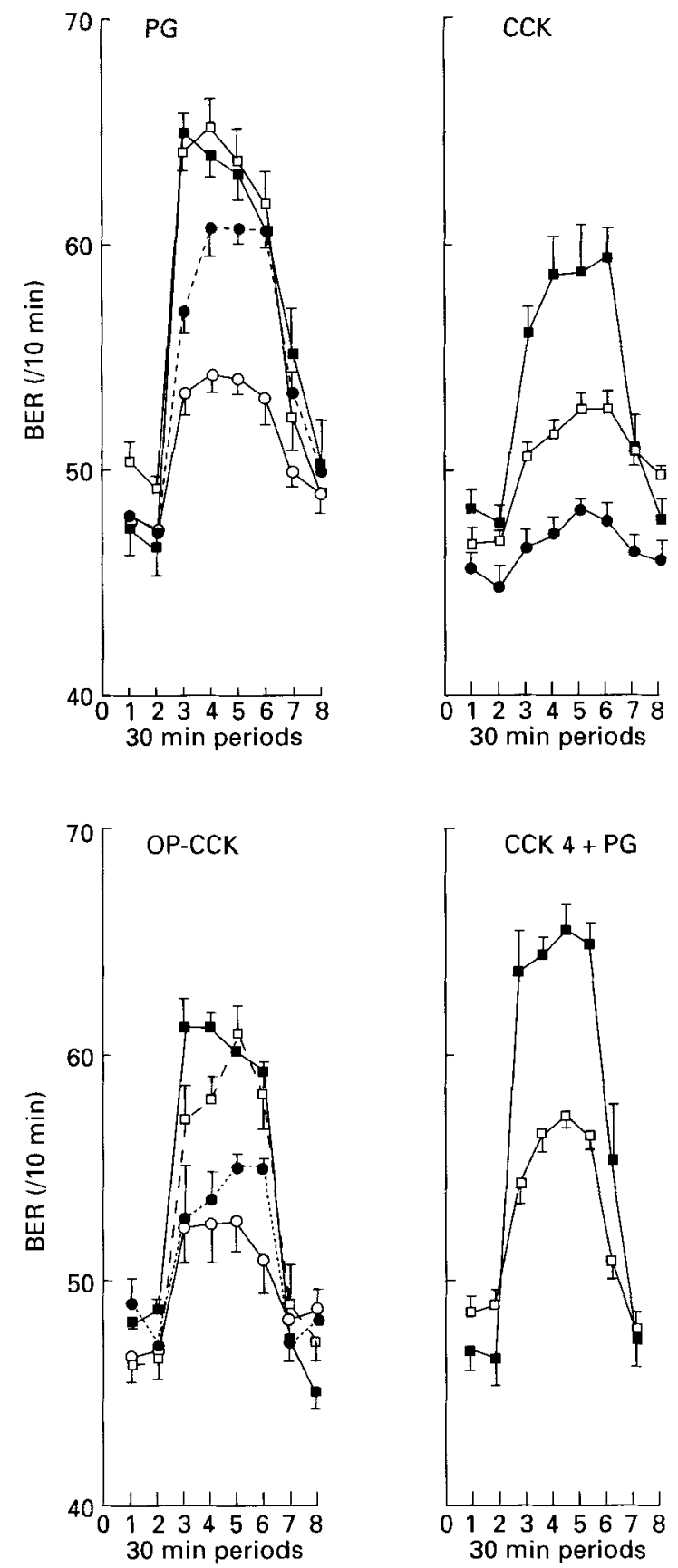

Fig. 3. Antral basal electrical rhythm (BER), before dosing (periods 1 and 2), in response to four doses of pentagastrin (PG; $\mu \mathrm{g} / \mathrm{kg}$ per $\mathrm{h} ;(\mathbf{G}) 32 ;(\square) 8 ;(\mathbf{O}) ; 4 ;(\mathrm{O}), 0.5)$, three doses of cholecystokinin $(\mathrm{CCK} ; \mathrm{Ivy}$ Dog

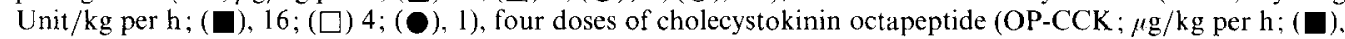

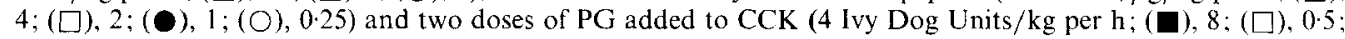
periods 3-6), and after cessation of the infusion (periods 7 and 8 ). An increase was produced by the three peptides. Points are means with their standard errors, represented by vertical bars, for six to nine experiments for three cats. For details of animals and procedures, see pp. 371-372. 


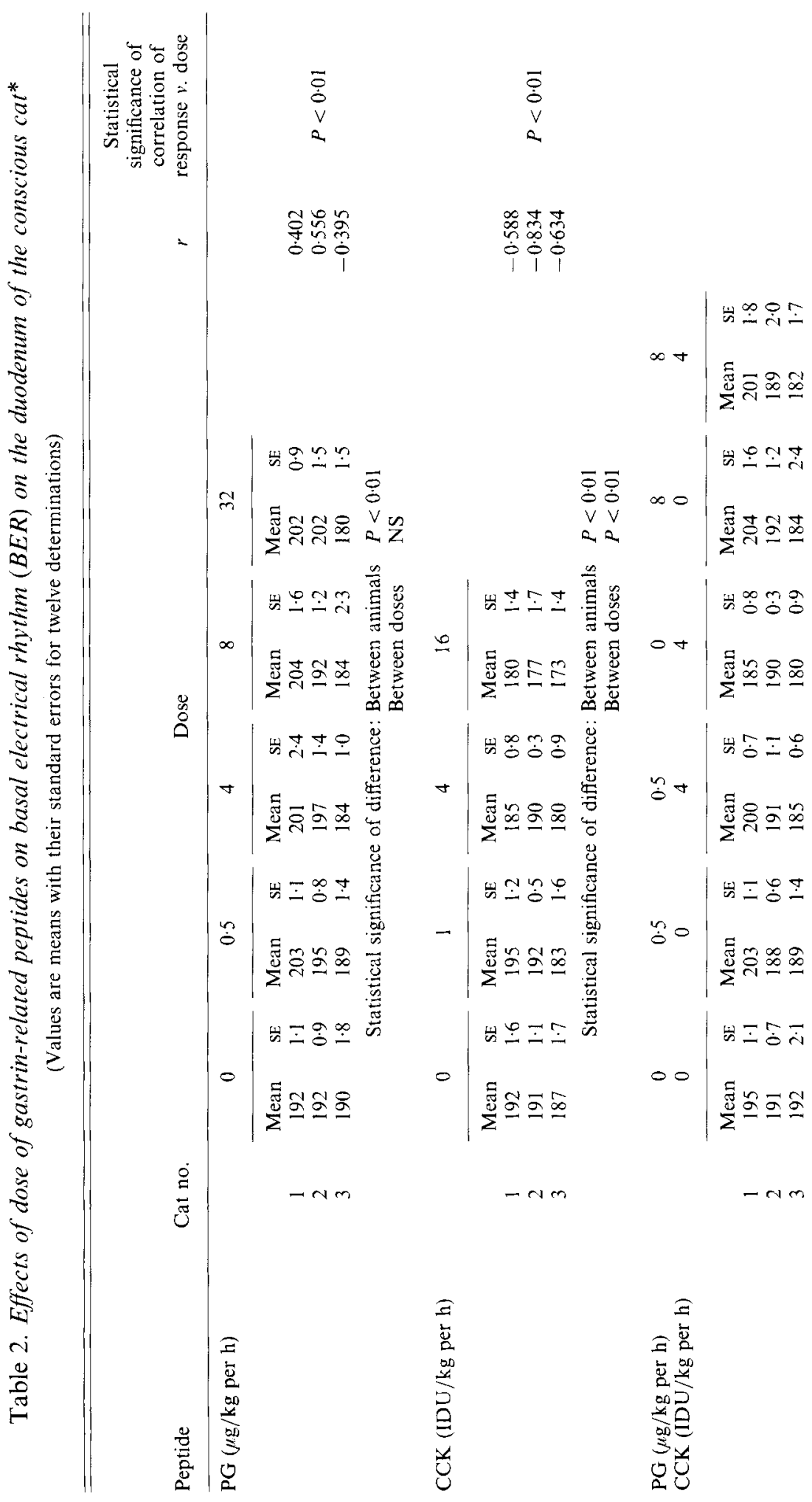




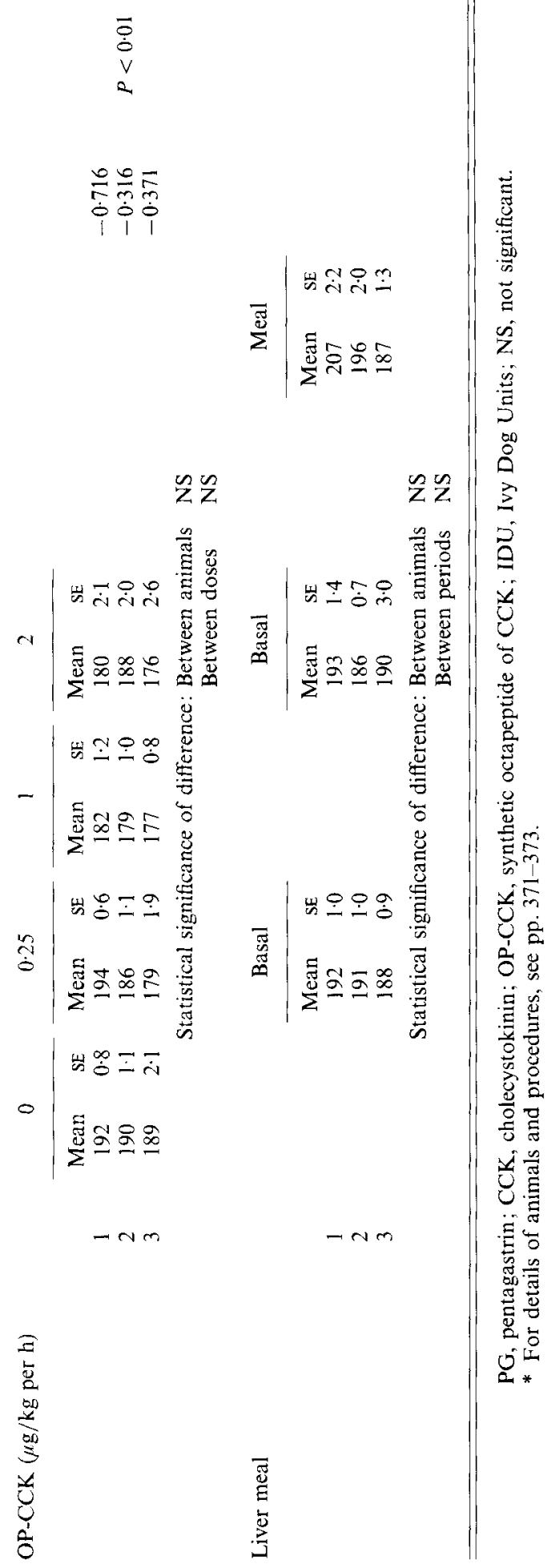



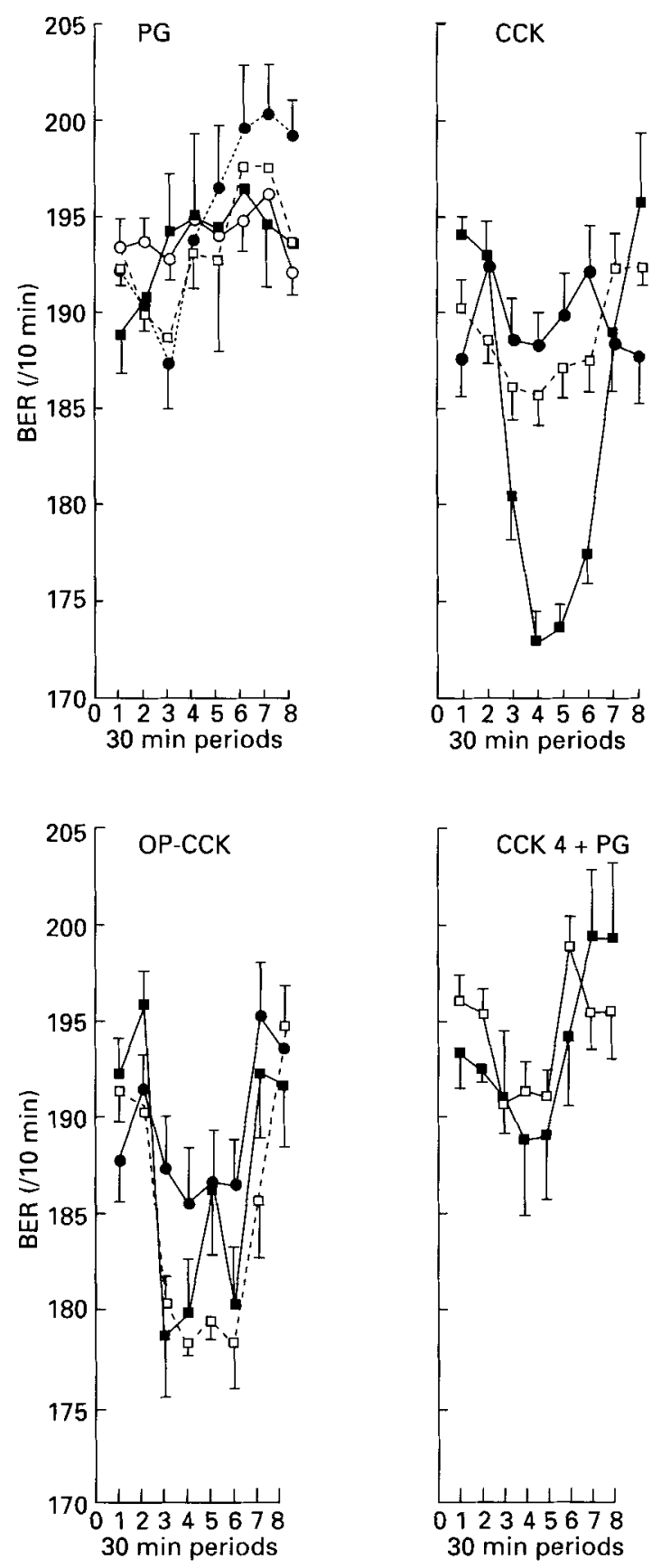

Fig. 4. Duodenal basal electrical rhythm (BER), before dosing (periods 1 and 2), in response to four doses of pentagastrin (PG; $\mu \mathrm{g} / \mathrm{kg}$ per $\mathrm{h} ;(\mathbf{D}), 32 ;(\square), 8 ;(\mathbf{O}), 4 ;(\mathrm{O}), 0 \cdot 5)$, three doses of $(t 2 \cdot 74$ and $3 \cdot 17)$ cholecystokinin (CCK; Ivy Dog Units/kg per $\mathrm{h} ;(\mathbf{\square}), 16 ;(\square), 4 ;(\mathbf{O}) 1$ ), three doses of cholecystokinin octapeptide (OP-CCK; $\mu \mathrm{g} / \mathrm{kg}$ per $\mathrm{h} ;(\mathbf{\square}), 2 ;(\square), 1 ;(\mathbf{O}), 0.25)$ and two doses of PG added to CCK (4 lvy Dog Units/kg per h; ( $), 8$; ( $\square$ ), 0.5 ; periods $3-6$ ), and after cessation of the infusion (periods 7 and 8 ). An increase was produced by the three peptides. Points are means with their standard errors, represented by vertical bars, for six to nine experiments for three cats. For details of animals and procedures, see pp. 371-372. 

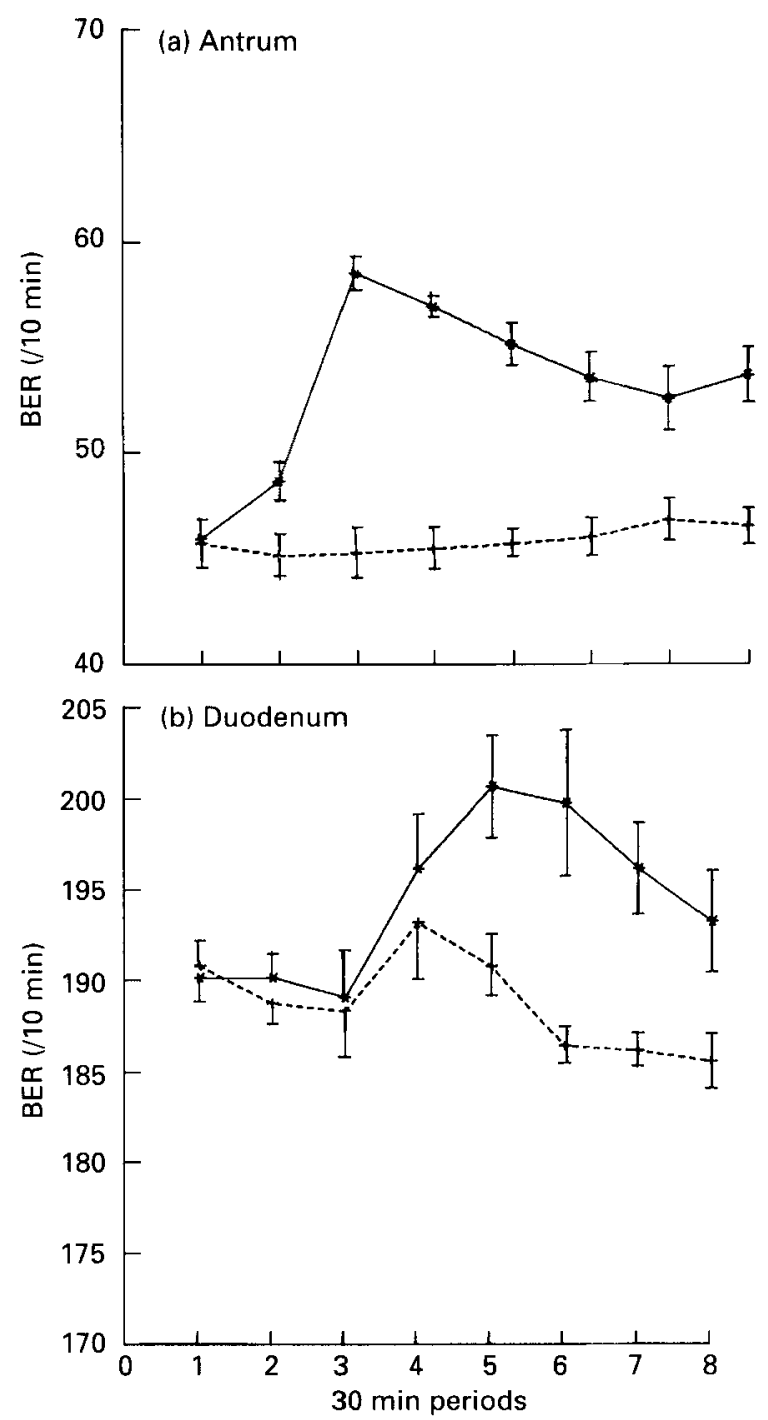

Fig. 5. Antral (a) and duodenal (b) basal electrical rhythm (BER) of conscious cats in response to a liver meal $(\stackrel{-}{-}$ : periods 1 and 2 , before the meal; periods $3-8$, after the meal. (---), Control values (without meal). The values are the means with their standard errors, represented by vertical bars, for nine experiments for three cats. For details of animals and procedures, see pp. 371-373.

bursts were associated with contractions of lower amplitude than those in the basal period (less than $200 \mathrm{~mm}$ water; Fig. 1).

Spiking activity on the duodenum. An increase in spiking activity was obtained with each of the peptides, corresponding to a permanent spiking activity during antral inhibition. After this primary effect, short bursts of spikes occurred at antral frequency.

\section{Postprandial patterns}

A large increase in BER at the antral level was observed after a fresh liver meal (Fig. 5). The multi-factorial analysis of variance showed no difference between animals (Table 1), 
Table 3. Effect of nature of meal on plasma gastrin concentration $(\mathrm{pg} / \mathrm{ml})$ of four conscious cats

(Mean values with their standard errors; no. of experiments per animal in parentheses)

\begin{tabular}{|c|c|c|c|c|c|c|c|c|c|}
\hline Meal & Cat no. & & & & & & & & \\
\hline \multirow[t]{3}{*}{$60 \mathrm{~g}$ canned food (2) } & & \multicolumn{8}{|c|}{ Period after meal (min) } \\
\hline & & \multicolumn{2}{|c|}{ Basal } & \multicolumn{2}{|c|}{30} & \multicolumn{2}{|c|}{60} & \multicolumn{2}{|c|}{90} \\
\hline & $\begin{array}{c}1 \\
2 \\
3 \\
4 \\
\text { Total }\end{array}$ & $\begin{array}{c}\text { Mean } \\
14 \\
24 \\
22 \\
20 \\
20\end{array}$ & $\begin{array}{r}\text { SE } \\
1 \\
10 \\
3 \\
4 \\
3\end{array}$ & $\begin{array}{c}\text { Mean } \\
101 \\
165 \\
103 \\
71 \\
110\end{array}$ & $\begin{array}{r}\text { SE } \\
6 \\
6 \\
10 \\
0 \\
13\end{array}$ & $\begin{array}{c}\text { Mean } \\
72 \\
122 \\
62 \\
69 \\
81\end{array}$ & $\begin{array}{l}\text { SE } \\
14 \\
10 \\
10 \\
12 \\
10\end{array}$ & $\begin{array}{c}\text { Mean } \\
84 \\
110 \\
69 \\
58 \\
80\end{array}$ & $\begin{array}{r}\mathrm{SE} \\
5 \\
6 \\
7 \\
3 \\
8\end{array}$ \\
\hline \multicolumn{10}{|c|}{$\begin{array}{l}\text { Statistical significance of difference: } \\
\text { Between basal and postprandial periods }\end{array}$} \\
\hline $\begin{array}{l}\text { Between animals } \\
\text { Between periods }\end{array}$ & & & & \multicolumn{2}{|c|}{$P<0.001$} & \multicolumn{2}{|c|}{$\begin{array}{l}P<0.001 \\
\quad \text { NS } \\
P<0.01\end{array}$} & \multicolumn{2}{|c|}{$P<0 \cdot 001$} \\
\hline \multirow[t]{3}{*}{$60 \mathrm{~g}$ beef liver ( 3 ) } & & & & \multicolumn{6}{|c|}{ Period after meal (min) } \\
\hline & & \multicolumn{2}{|c|}{ Basal } & \multicolumn{2}{|c|}{30} & \multicolumn{2}{|c|}{60} & \multicolumn{2}{|c|}{90} \\
\hline & $\begin{array}{c}1 \\
2 \\
3 \\
4 \\
\text { Total }\end{array}$ & $\begin{array}{c}\text { Mean } \\
21 \\
16 \\
31 \\
32 \\
27\end{array}$ & $\begin{array}{r}\mathrm{SE} \\
4 \\
4 \\
5 \\
3 \\
2\end{array}$ & $\begin{array}{c}\text { Mean } \\
277 \\
335 \\
350 \\
350 \\
328\end{array}$ & $\begin{array}{l}\mathrm{SE} \\
30 \\
10 \\
10 \\
48 \\
15\end{array}$ & $\begin{array}{l}\text { Mean } \\
292 \\
215 \\
300 \\
257 \\
266\end{array}$ & $\begin{array}{l}\text { SE } \\
47 \\
51 \\
55 \\
15 \\
21\end{array}$ & $\begin{array}{c}\text { Mean } \\
228 \\
158 \\
315 \\
225 \\
224\end{array}$ & $\begin{array}{r}\text { SE } \\
42 \\
15 \\
5 \\
33 \\
21\end{array}$ \\
\hline \multicolumn{10}{|c|}{ Between basal and postprandial periods } \\
\hline $\begin{array}{l}\text { Between animals } \\
\text { Between periods }\end{array}$ & & & & \multicolumn{2}{|c|}{$P<0.001$} & \multicolumn{2}{|c|}{$\begin{array}{l}P<0.001 \\
\quad \text { NS } \\
P<0.01\end{array}$} & \multicolumn{2}{|c|}{$P<0.001$} \\
\hline \multicolumn{10}{|c|}{$\begin{array}{l}\text { Comparison of the delta plasma gastrin ( } 30 \mathrm{~min} \text { gastrinaemia minus basal gastrinaemia) induced by the } 2 \\
\text { meals: }\end{array}$} \\
\hline $\begin{array}{l}60 \mathrm{~g} \text { canned food } \\
60 \mathrm{~g} \text { beef liver }\end{array}$ & & $\begin{array}{c}\text { Mean } \\
84 \\
276\end{array}$ & $\begin{array}{l}\text { SE } \\
27 \\
22\end{array}$ & & & & & & \\
\hline $\begin{array}{l}\text { Statistical significar } \\
\text { Between animals } \\
\text { Between meals }\end{array}$ & & & & & & $\begin{aligned} \text { NS } \\
P<0 \cdot\end{aligned}$ & 0001 & & \\
\hline
\end{tabular}

but a statistically significant difference between basal and postprandial BER frequency. In the duodenum the increase was not significant (Table 2).

Feeding increased the mean level of spiking activity; spike bursts were superimposed on $75 \%$ of the antral slow waves from 0 to 15 min after feeding compared with $35 \%$ in the control period. On the duodenum, spike bursts were superimposed on $82 \%$ of the slow waves.

\section{Role of the nature of the meal on gastrin release}

Table 3 shows the differences in gastrin release induced by the two different meals. The fresh liver meal was a much stronger releaser of gastrin in the cat, while canned food 
released only $30 \%$ of the amount released by liver. Both meals induced a statistically significant increase in basal gastrinaemia (Table 3) without any significant variation between animals.

\section{DISCUSSION}

The present study has shown that in the cat all three structurally related gastrin peptides, PG, CCK and OP-CCK, have the same effect on the EMG recordings of the antrum in inducing an increase in BER and a short-lasting decrease in the frequency of the bursts of spikes. These electrical changes, already described for gastrin in man (Kwong et al. 1972) and in the dog (Bueno \& Garcia-Villar, 1979), are well correlated with pressure changes obtained by manometric measurements run in parallel in the same animals and demonstrating a decrease of the high-amplitude contractions and an increase of lowamplitude peaks, confirming our previous findings (Desvigne et al. 1980). A supra-maximal dose does not decrease the response, as illustrated by the response to $32 \mu \mathrm{g}$ PG. All three gastrointestinal peptides are full agonists of the electrical activity of the antrum as well as of antral motility (Desvigne et al. 1980) and acid secretion (Way, 1971), but not of pepsin secretion. On the other hand, the three peptides are not full agonists of duodenal motility since PG increased slightly the BER at the duodenal level, while the other two decreased BER significantly.

There seems to be a certain discrepancy between pressure and EMG recordings as far as the duration of the effects is concerned. It has been shown, on the basis of pressure findings, that the motor effect of the peptides was well maintained during a continuous $2 \mathrm{~h}$ infusion (Desvigne et al. 1980). However, the frequency of the bursts of spiking activity, after a short-lasting decrease, increased in spite of the continuous peptide administration. In fact, the simultaneous recordings clearly showed that there is a dissociation between frequency and amplitude. The bursts of spiking activity are associated with contractions of lower amplitude (less than $200 \mathrm{~mm}$ water pressure) than during the basal period (200 to $400 \mathrm{~mm}$ water pressure).

There is a species difference since in dog it has been shown that CCK, unlike PG, does not induce any change in BER (Wingate et al. 1978). This species difference might be secondary to acid secretion, as pointed out by Wingate et al. (1978). BER frequency has been shown to be sensitive to acid in man (Couturier et al. 1973). However, under our experimental conditions, gastric juice was continuously collected by a gastric cannula placed in the declivitous part of the fundus.

In contrast to the antrum, the three peptides increased the frequency of the duodenal spike bursts and a decrease in BER frequency was observed with CCK and OP-CCK, while PG increased BER slightly. These findings in cat contrast with those reported in dogs in which PG induces a great increase in BER while CCK does not provoke any change (Wingate et al. 1978).

Our findings indicate that gastrin, which has the same effects as PG, might play a role in the electrical changes observed after a liver meal which releases three times more gastrin than a regular canned meal, but it is not known whether the effect is direct or secondary to the acid secretion.

The difference in gastrin release observed during different meals clearly explains why a beef-liver meal but not a canned meal induced an increase in BER of the antrum, as already demonstrated in an earlier study (Roche et al. 1982). Thus, it is possible to correlate in the cat the release of endogenous gastrin induced by the food with the increase in BER in the antrum and the increase in low-amplitude contractions which allow a good mixing of the gastric contents (Strunz \& Grossman, 1977). Gastrin and CCK are known to slow down 
gastric emptying and it has been suggested that this inhibition of emptying by gastrin is due to fundic relaxation (Ruppin \& Domschke, 1980). Recent data have shown a relationship between emptying of liquids and motor function of the antropyloric region (Dooley \& Valenzuela, 1988; Chikh-Issa et al. 1989). The localization of CCK receptors directly on the muscle of the pyloric sphincter (Smith et al. 1984) favours a direct role of the pyloric sphincter in the inhibition of gastric emptying produced by CCK, mediated by a capsaicinsensitive vagal afferent pathway in the rat (Raybould \& Taché, 1988). However, in the cat gastrin appears to play a major role in antral motility induced by a meal. It is not known whether the effect of gastrin in the cat is mediated by a vagal pathway, as has been shown for $\mathrm{CCK}$ in the rat.

The expert technical assistance of A. Desvigne, M. Collinet, C. Bernard and G. Jourdan is gratefully acknowledged. The authors also wish to thank Dr M. J. Carew for reviewing the English manuscript.

\section{REFERENCES}

Bueno, L. \& Garcia-Villar, R. (1979). Secretory and motor activities at the gastroduodenal junction in dogs. Veterinary Science Communications 3, 249-256.

Chikh-Issa, A. R., Scarpignato, C., Collinet, M., Chayvialle, J. A. \& Vagne, M. (1989). Dual effect of bombesin and gastrin releasing peptide on gastric emptying in conscious cats. Peptides 10, 281-287.

Couturier, D., Rozé, C., Vasconcellos, D., Accary, J. P. \& Debray, C. (1973). Effect of acid in stomach and duodenum upon the gastric myoelectrical activity in man. Digestion 9, 502-513.

Desvigne, C., Gelin, M. L., Vagne, M. \& Roche, M. (1980). Effect of Cholecystokinin and Pentagastrin on motility and gastric secretion in the cat. Digestion 20, 265-276.

Dooley, C. P. \& Valenzuela, J. E. (1988). Antropyloroduodenal activity during gastric emptying of liquid meals in humans. American Journal of Physiology 255, G93 G98.

Hunter, W. M.\& Greenwood, F. C. (1962). Preparation of iodine-131 labelled human growth hormone with high specific activity. Nature $194,495-496$.

Kwong, N. K., Brown, B. H., Whittaker, G. E. \& Duthie, H. L. (1972). Effects of Gastrin I, Secretin and Cholecystokinin-Pancreozymin on the electrical activity, motor activity and acid output of the stomach in man. Scandinavian Journal of Gastroenterology 7, 161-170.

Raybould, H. E. \& Taché, Y. (1988). Cholecystokinin inhibits gastric motility and emptying via a capsaicinsensitive vagal pathway in rats. American Journal of Physiology 255, G242-G246.

Roche, M., Bueno, L., Vagne, M. \& Blourde, C. (1982). Patterns of electrical activity in the digestive tract of the conscious cat. British Journal of Nutrition 48, 129-135.

Ruppin, H. \& Domschke, W. (1980). Gastrointestinal hormones and motor function of the gastrointestinal tract. In Gastrointestinal Hormones, pp. 587-612 [G. B. Jerzy Glass, editor]. New York: Raven Press.

Smith, G. T, Moran, T. H., Coyle, J. T., Kuhar, M. J., O’Donahue, T. L. \& McHugh, P. R. (1984),. Anatomic localization of cholecystokinin receptors to the pyloric sphincter. American Journal of Physiology 246, R127-R130.

Strunz, U. T. \& Grossman, M. I. (1977). In Nerves of the Gut, pp. 233-245 [F. P. Brooks and P. W. Evers, editors]. Thorofare, N.J.: C. B. Slack Inc.

Thomas, J. E. (1941). An improved cannula for gastric and intestinal fistulas. Proceedings of the Society for Experimental Biology and Medicine 46, 359-364.

Vagne, M., Gelin, M. L., McDonald, T. J., Chayvialle, J. A. \& Minaire, Y. (1982). Effect of Bombesin on gastric secretion and motility in the cat. Digestion 24, 5-13.

Vagne, M., Collinet, M., Cuber, J. C., Bernard, C., Chayvialle, J. A., McDonald, T. J. \& Mutt, V. (1987). Effect of porcine Gastrin Releasing Peptide on gastric secretion and motility and the release of hormonal peptides in conscious cats. Peptides $\mathbf{8}, 423-430$.

Way, L. (1971). Effect of cholecystokinin and caerulein on gastric secretion in cats. Gastroenterology 60, 560-565.

Wingate, D. L., Pearce, E. A., Hutton, M., Dand, A., Thompson, H. H. \& Wunsch, E. (1978). Quantitative comparison of the effects of cholecystokinin, secretin and pentagastrin on gastrointestinal myoelectric activity in the conscious fasted dog. Gut 19, 593-601. 